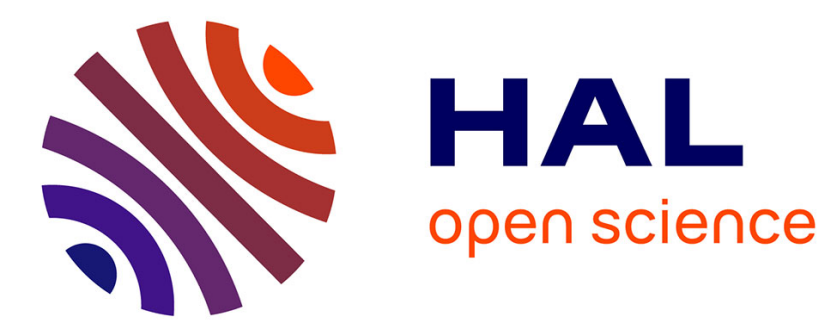

\title{
Observer-based Control for Linear Sampled-Data Systems: An Impulsive System Approach
}

Héctor Ríos, Laurentiu Hetel, Denis Efimov

\section{To cite this version:}

Héctor Ríos, Laurentiu Hetel, Denis Efimov. Observer-based Control for Linear Sampled-Data Systems: An Impulsive System Approach. Proc. 55th IEEE Conference on Decision and Control (CDC), Dec 2016, Las Vegas, United States. hal-01371272

\section{HAL Id: hal-01371272 \\ https://hal.inria.fr/hal-01371272}

Submitted on 25 Sep 2016

HAL is a multi-disciplinary open access archive for the deposit and dissemination of scientific research documents, whether they are published or not. The documents may come from teaching and research institutions in France or abroad, or from public or private research centers.
L'archive ouverte pluridisciplinaire HAL, est destinée au dépôt et à la diffusion de documents scientifiques de niveau recherche, publiés ou non, émanant des établissements d'enseignement et de recherche français ou étrangers, des laboratoires publics ou privés. 


\title{
Observer-based Control for Linear Sampled-Data Systems: An Impulsive System Approach
}

\author{
Héctor Ríos ${ }^{\dagger}$, Laurentiu Hetel ${ }^{\ddagger}$ and Denis Efimov ${ }^{\S^{*}}$
}

\begin{abstract}
This paper deals with the sampled-data control problem based on state estimation for linear sampled-data systems. An impulsive system approach is proposed based on a vector Lyapunov function method. Observer-based control design conditions are expressed in terms of LMIs. Some examples illustrate the feasibility of the proposed approach.
\end{abstract}

Index Terms-Observer-based Control, Sampled-Data and Impulsive systems.

\section{INTRODUCTION}

$\mathbf{I}$ $\mathrm{N}$ the last decades, an enormous interest has appeared in the design of controllers and observers for continuous and/or discrete dynamical systems with communication constraints. This interest has its motivations in systems with sampled-data control, quantization and more generally, in networked control systems. However, all the communications constraints, i.e. delays, sampling intervals, quantization, packet dropouts, and so on (for details, see [13]); imply additional difficulties in the analysis and design compared to the classical control systems. Regarding the observer design problem, one of the main issues is the scheduling: only a subset of sensors is allowed to send their data to the observer at the transmission instants. The sporadic and partial availability of system measurements requires the development of appropriate observer designs. Moreover, for controller design, it would be unreasonable to assume that all states are measurable. Therefore an observer-based control approach is needed.

In this paper the observer-based control problem will be focused on sampled-data systems. Several methods have been developed to study sampled-data systems, e.g. the Input/Output stability approach [12], the discrete-time approach [11], but two approaches stand out: the input delay

\footnotetext{
${ }^{\dagger}$ Electrical \& Computer Engineering, University of USA. Email hector_riosbarajas@ece.ucsb.edu

$\ddagger$ CRIStAL (UMR-CNRS 9189), Ecole Centrale de Lille, BP 48, Cité Scientifique, 59651 Villeneuve-d'Ascq, France. Email: laurentiu.heteldec-lille.fr

§Non-A team @ Inria, Parc Scientifique de la Haute Borne, 40 avenue Halley, 59650 Villeneuve d'Ascq, France; and CRIStAL (UMR-CNRS 9189), Ecole Centrale de Lille, BP 48, Cité Scientifique, 59651 Villeneuved'Ascq, France. Emails: denis.efimoveinria.fr

* Department of Control Systems and Informatics, Saint Petersburg State University of Information Technologies Mechanics and Optics (ITMO), Kronverkskiy av. 49, Saint Petersburg, 197101, Russia.
}

approach, where the system is modeled as a continuous system with a delay in the control input (see, e.g. [9], [8]), and the impulsive system approach, where the sampled-data system is treated as an impulsive system (see, e.g. [20], [5], [4], [3]).

The input delay approach has been applied in [10] to design a sampled-data output-feedback $H_{\infty}$ control for linear systems while the impulsive system approach was applied in [14] to sampled-data stabilization of linear uncertain systems in the case of constant sampling based on piece-wise linear in time Lyapunov function. The case of variable sampling based on a discontinuous Lyapunov function method was introduced by [16]. Also based on discontinuous Lyapunov functions, in [3] stability and stabilization conditions for periodic and aperiodic sampled-data systems are introduced.

In the context of observer design, one approach is based on continuous and discrete design. In [7], such an approach is used to design a discrete-continuous version of the highgain observer for nonlinear systems. Based on a small gain approach, in [1] an observer design is proposed for certain classes of nonlinear systems with sampled and delayed measurements. Using the hybrid system approach, in [6] an observer-protocol pair is designed to estimate the states of a linear system under communication constraints induced by the network. Adopting a switched observer structure, in [2] decentralized observer-based output-feedback controllers are proposed for linear systems connected via a shared communication network.

In this paper a vector Lyapunov function-based approach [15] for stability of impulsive systems is used to design an observer-based control for linear sampled-data systems. Such an approach, proposed by [17] and [18], is based on a $2 D$ time domain equivalence (see, e.g. [19] and [21]), and provides a stability analysis based on linear matrix inequalities (LMIs) for linear impulsive dynamical systems. It is possible to show that the sampled-data control problem based on state estimation may turn into one of finding conditions for the exponential stability of impulsive systems. Then, this vector Lyapunov function approach is applied to find such conditions expressed in terms of LMIs, and solve the proposed problem for linear sampled-data systems.

The outline of this work is as follows. A motivating problem is given in Section II. Some preliminary results are given in Section III. The main result is described in Section IV. Some simulation results are depicted in Section 
V. Finally, some concluding remarks are discussed in Section VI.

\section{Motivation}

Let us consider the following sampled-data system

$$
\begin{aligned}
\dot{x}(t) & =A x(t)+B u(t), \\
y(t) & =C x\left(t_{i}\right), \forall t \in\left[t_{i}, t_{i+1}\right), \\
u(t) & =-K \hat{x}\left(t_{i}\right), \forall t \in\left[t_{i}, t_{i+1}\right),
\end{aligned}
$$

where $x \in \mathbb{R}^{n}$ is the state vector, $u \in \mathbb{R}^{m}$ is the sampled control vector, and $y \in \mathbb{R}^{p}$ is the sampled output vector at each time $t_{i}$ for all $i \in \mathbb{N}$, and $\hat{x} \in \mathbb{R}^{n}$ represents an estimation of the system state $x$. The sampling instants $t_{i}$ are monotonously increasing, such that $\lim _{i \rightarrow \infty} t_{i}=+\infty$, and $t_{i+1}-t_{i} \in\left[T_{\min }, T_{\max }\right]$, where $T_{\min }$ and $T_{\max }$ are the minimum and maximum sampling intervals, respectively; and $t_{0}=0$. The constant matrices $A, B$, and $C$ have corresponding dimensions while $K$ is a design control matrix. The control $u$ is designed by means of the following sampled-data state observer

$$
\begin{aligned}
\dot{\hat{x}}(t)=A \hat{x}(t)+ & B u(t) \\
& +L\left(y(t)-C \hat{x}\left(t_{i}\right)\right), \forall t \in\left[t_{i}, t_{i+1}\right),
\end{aligned}
$$

where $\hat{x} \in \mathbb{R}^{n}$ is the estimated state vector and $L$ is a design observer matrix. Define the state estimation error $e(t)=x(t)-\hat{x}(t)$. Then, the closed-loop and state estimation error dynamics are given as follows

$$
\begin{aligned}
& \dot{x}(t)=A x(t)-B K x\left(t_{i}\right)+B K e\left(t_{i}\right), \forall t \in\left[t_{i}, t_{i+1}\right), \\
& \dot{e}(t)=A e(t)-L C e\left(t_{i}\right), \forall t \in\left[t_{i}, t_{i+1}\right) .
\end{aligned}
$$

Let us define the extended state vector $\xi(t)=$ $\left(x^{T}(t) e^{T}(t) \quad x^{T}\left(t_{i}\right) \quad e^{T}\left(t_{i}\right)\right)^{T} \in \mathbb{R}^{4 n}$. Thus, the above dynamics may be written as follows

$$
\begin{aligned}
& \dot{\xi}(t)=A_{\xi} \xi(t), \forall t \in \mathbb{R}_{+} \backslash \mathbb{I}, \\
& \xi(t)=I_{\xi} \xi\left(t^{-}\right), \forall t \in \mathbb{I},
\end{aligned}
$$

where $\mathbb{I}:=\left\{t_{i}\right\}_{i \in \mathbb{N}}$ is a set of impulse times, $\xi(t) \in \mathbb{R}^{4 n}$ is the current state vector, $\xi\left(t_{i}\right) \in \mathbb{R}^{4 n}$ represents the reset vector state, $\xi\left(t_{i}^{-}\right) \in \mathbb{R}^{4 n}$ denotes the value of $\xi$ just before the impulse at time $t_{i}$, i.e. $\xi\left(t_{i}^{-}\right)=\lim _{t \uparrow t_{i}} \xi(t)$, and the corresponding matrices have the following structure

$$
\begin{gathered}
A_{\xi}=\left(\begin{array}{cccc}
A & \mathbf{0} & -B K & B K \\
\mathbf{0} & A & \mathbf{0} & -L C \\
\mathbf{0} & \mathbf{0} & \mathbf{0} & \mathbf{0} \\
\mathbf{0} & \mathbf{0} & \mathbf{0} & \mathbf{0}
\end{array}\right), \\
I_{\xi}=\left(\begin{array}{cccc}
I_{n} & \mathbf{0} & \mathbf{0} & \mathbf{0} \\
\mathbf{0} & I_{n} & \mathbf{0} & \mathbf{0} \\
I_{n} & \mathbf{0} & \mathbf{0} & \mathbf{0} \\
\mathbf{0} & I_{n} & \mathbf{0} & \mathbf{0}
\end{array}\right) .
\end{gathered}
$$

Then, the sampled-data control problem based on state estimation, i.e. find the control gain matrix $K$ and the observer gain matrix $L$, may turn into one of finding conditions for the stability of the impulsive systems described by (5)-(6), under arbitrary variations of the sampling intervals.

\section{Stability Analysis FOR ImpUlsive Systems}

The entire state trajectory $\left(\xi^{T}, \tau\right)^{T}$ can be viewed as a sequence of the diagonal dynamics ${ }^{1}$ of the following $2 D$ system:

$$
\begin{aligned}
& \frac{d}{d t}\left(\begin{array}{c}
\xi_{k}^{t} \\
\tau_{k}^{t}
\end{array}\right)=\left(\begin{array}{c}
A_{\xi} \xi_{k}^{t} \\
1
\end{array}\right), \forall \tau_{k}^{t} \in\left[0, T_{i}\right], \forall i=k \in \mathbb{N}, \\
& \left(\begin{array}{c}
\xi_{k+1}^{t_{i+1}} \\
\tau_{k+1}^{t_{i+1}}
\end{array}\right)=\left(\begin{array}{c}
I_{\xi} \xi_{k}^{t_{i+1}} \\
0
\end{array}\right), \forall \tau_{k}^{t}=T_{i}, \forall i=k \in \mathbb{N},
\end{aligned}
$$

where $\tau \in \mathbb{R}_{\geq 0}$ is a timer variable, $\left(\left(\xi_{k}^{t}\right)^{T}, \tau_{k}^{t}\right)^{T}=$ $\left(\xi^{T}(t, k), \tau(t, k)\right)^{T} \in \mathbb{R}^{4 n+1}$ is the current state vector, $\left(\left(\xi_{k+1}^{t_{i+1}}\right)^{T}, \tau_{k+1}^{t_{i+1}}\right)^{T}=\left(\xi^{T}\left(t_{i+1}, k+1\right), \tau\left(t_{i+1}, k+\right.\right.$ 1) $)^{T} \in \mathbb{R}^{4 n+1}$ represents the reset state vector, while $\left(\left(\xi_{k}^{t_{i+1}}\right)^{T}, \tau_{k}^{t_{i+1}}\right)^{T}=\left(\xi^{T}\left(t_{i+1}, k\right), \tau\left(t_{i+1}, k\right)\right)^{T} \in \mathbb{R}^{4 n+1}$ denotes the value of $\left(\xi^{T}, \tau\right)^{T}$ just before the jump $k+1$. It is assumed that the solutions of (7)-(8) are unique for the diagonal dynamics, i.e. for all $i=k$.

Remark 1. In this approach the model (5)-(6) corresponds only to the sequence of diagonal dynamics of the $2 D$ model (7)-(8). This model transformation is used to obtain sufficient conditions for stability, based on vector Lyapunov functions. An equivalence between models is not required since necessary and sufficient conditions are not provided.

In the present section some definitions and results for the stability of impulsive systems, in the framework of $2 D$ systems, are introduced (see [18]).

Let $|q|$ denote the Euclidean norm of a vector $q$. The following stability definition is introduced:

Definition 1. [18]. A 2D system described by (7)-(8), is said to be exponentially diagonal $\xi_{k}^{t}$-stable $\left(\operatorname{ED} \xi_{k}^{t}-\mathrm{S}\right)$ if there exist positive constants $\kappa_{1}, \kappa_{2}, \kappa_{3}$, and c such that $0<\kappa_{1}<1$ and

$$
\begin{gathered}
\left|\xi_{k+1}^{t_{i+1}}\right|^{2} \leq c \kappa_{1}^{k+1}\left|\xi_{0}^{0}\right|^{2}, \quad \forall \tau_{k}^{t}=T_{i} \\
\left|\xi_{k}^{t}\right|^{2} \leq \kappa_{2}\left|\xi_{k}^{t_{i}}\right|^{2}, \forall \tau_{k}^{t} \in\left[0, T_{i}\right] \\
\left|\tau_{k}^{t}\right| \leq \kappa_{3}
\end{gathered}
$$

for all $i=k \in \mathbb{N}$.

Note that condition (11) holds by definition, i.e. $\left|\tau_{k}^{t}\right| \leq \kappa_{3}$, with $\kappa_{3}=T_{\max }$. Denote $z_{k}^{t}:=\left(\left(\xi_{k}^{t}\right)^{T}, \tau_{k}^{t}\right)^{T}$. In order to give the stability conditions a vector Lyapunov approach is used ${ }^{2}$, i.e.

$$
V\left(z_{k}^{t}, z_{k+1}^{t_{i+1}}\right)=\left(\begin{array}{c}
V_{1}\left(z_{k}^{t}\right) \\
V_{2}\left(z_{k+1}^{t_{k+1}}\right)
\end{array}\right)
$$

where $V_{1}(\cdot)>0, V_{2}(\cdot)>0$, for all $t \geq 0$, and $V_{1}(0)=0$, $V_{2}(0)=0$. Now, let us introduce the following definition.

Definition 2. The divergence operator of a function $V$ along the trajectories of system (7)-(8) is defined for all

\footnotetext{
${ }^{1}$ The diagonal dynamics make reference only to those dynamics given by (7)-(8) corresponding to $i=k$, for all $i, k \in \mathbb{N}$ and for all $t \in \mathbb{R}_{\geq 0}$.

${ }^{2}$ The use of vector Lyapunov functions offers a more flexible framework since each component of the vector Lyapunov function can satisfy less rigid requirements as compared to a single Lyapunov function (see e.g. [15]).
} 
$t \in\left[t_{i}, t_{i+1}\right)$ as follows

$$
\operatorname{div} V\left(z_{k}^{t}, z_{k+1}^{t_{i+1}}\right)=\frac{d V_{1}\left(z_{k}^{t}\right)}{d t}+V_{2}\left(z_{k+1}^{t_{i+1}}\right)-V_{2}\left(z_{k}^{t_{i+1}}\right) .
$$

Note that $V_{1}$ is differentiable with respect to continuous time $t$ while the difference in $V_{2}$ is calculated in discrete time $k$. Thus, the following theorem is introduced.

Theorem 1. [18]. Assume that there exist positive constants $c_{1}, c_{2}, c_{3}, c_{4}$ and $c_{5}$ such that the vector Lyapunov function $V\left(z_{k}^{t}, z_{k+1}^{t_{i+1}}\right)$ and its divergence along the trajectories of the system (7)-(8) satisfy, for all $\tau_{k}^{t} \in\left[0, T_{i}\right], i=k \in \mathbb{N}$, the following inequalities:

$$
\begin{gathered}
c_{1}\left|\xi_{k}^{t}\right|^{2} \leq V_{1}\left(z_{k}^{t}\right) \leq c_{2}\left|\xi_{k}^{t}\right|^{2}, \\
c_{3}\left|\xi_{k}^{p}\right|^{2} \leq V_{2}\left(z_{k}^{p}\right) \leq c_{4}\left|\xi_{k}^{p}\right|^{2}, \forall p=t_{i}, t_{i+1} \\
\operatorname{div} V \leq-c_{5}\left(\left|\xi_{k}^{t}\right|^{2}+\left|\xi_{k}^{t_{i+1}}\right|^{2}\right), \\
c_{2}\left(c_{4}-c_{5}\right) \leq c_{1} c_{5} \vee T_{i} \leq \frac{c_{2}}{c_{5}} \alpha \\
\frac{c_{2}}{c_{5}} \gamma \leq T_{i},
\end{gathered}
$$

where $\gamma=-\ln \left[\frac{c_{3}}{c_{5}+c_{3}}\right]$ and $\alpha=-\ln \left[1-\frac{c_{1} c_{5}}{c_{2}\left(c_{4}-c_{5}\right)}\right]$ for all $c_{2}\left(c_{4}-c_{5}\right)>c_{1} c_{5}$. Then, the $2 D$ system (7)-(8) is $\mathrm{ED} \xi_{k}^{t}-\mathrm{S}$ for any sequence $\left\{T_{i}\right\}_{i \in \mathbb{N}}$ such that $T_{i} \in\left[\frac{c_{2}}{c_{5}} \gamma, \frac{c_{2}}{c_{5}} \alpha\right]$.

\section{A. Exponential Diagonal $\xi_{k}^{t}$-Stability: Quadratic Lyapunov Functions}

Consider that $V_{1}$ and $V_{2}$ take the following quadratic structure

$$
V\left(z_{k}^{t}, z_{k+1}^{t_{i+1}}\right)=\left(\begin{array}{c}
\left(\xi_{k}^{t}\right)^{T} P_{1}\left(\tau_{k}^{t}\right) \xi_{k}^{t} \\
\left(\xi_{k+1}^{t_{i+1}}\right)^{T} P_{2}\left(\tau_{k+1}^{t_{i+1}}\right) \xi_{k+1}^{t_{i+1}}
\end{array}\right)
$$

where $P_{1}$ is continuously differentiable with respect to $t$, symmetric, bounded, and positive definite matrix for all $\tau_{k}^{t} \in$ $\left[0, T_{i}\right], i=k \in \mathbb{N}$, while $P_{2}$ is a symmetric and positive definite matrix, i.e.

$$
\begin{aligned}
& 0<c_{1} I \leq P_{1}\left(\tau_{k}^{t}\right) \leq c_{2} I, \forall \tau_{k}^{t} \in\left[0, T_{i}\right], \\
& 0<c_{3} I \leq P_{2}\left(\tau_{k}^{p}\right) \leq c_{4} I, p=t_{i}, t_{i+1} .
\end{aligned}
$$

Thus, based on the previous choice for $V_{1}$ and $V_{2}$, if Theorem 1 is applied to the ideal and uncertain impulsive system (5)-(6), then the following result is obtained.

Corollary 1. Consider the vector Lyapunov function $V\left(z_{k}^{t}, z_{k+1}^{t_{i+1}}\right)$ in (18). Assume that there exist matrices $P_{1}\left(\tau_{k}^{t}\right)=P_{1}^{T}\left(\tau_{k}^{t}\right)>0$, continuously differentiable on $t$ and bounded for all $\tau_{k}^{t} \in\left[0, T_{i}\right], i=k \in \mathbb{N}, P_{2}(0)=P_{2}^{T}(0)>0$ and $P_{2}\left(T_{i}\right)=P_{2}^{T}\left(T_{i}\right)>0$ satisfying (19)-(20), and $a$ constant $c_{5}>0$, such that the following matrix inequality

$$
\left(\begin{array}{cc}
P_{1}\left(\tau_{k}^{t}\right) A_{\xi}+A_{\xi}^{T} P_{1}\left(\tau_{k}^{t}\right) & \mathbf{0} \\
+\frac{d P_{1}(t)}{d t}+c_{5} I_{4 n} & I_{\xi}^{T} P_{2}(0) I_{\xi} \\
\mathbf{0} & -P_{2}\left(T_{i}\right)+c_{5} I_{4 n}
\end{array}\right) \leq 0
$$

holds for all $\tau_{k}^{t} \in\left[0, T_{i}\right]$, for all $i=k \in \mathbb{N}$, and constraints
(16)-(17) are satisfied with $c_{1}, c_{2}, c_{3}, c_{4}$ and $c_{5}$. Then the system (7)-(8), with $f=0$, is $\mathrm{ED} \xi_{k}^{t}-\mathrm{S}$ for any sequence $\left\{T_{i}\right\}_{i \in \mathbb{N}}$ such that $T_{i} \in\left[\frac{c_{2}}{c_{5}} \gamma, \frac{c_{2}}{c_{5}} \alpha\right]$.

Now the goal is to apply the conditions for exponential diagonal $\xi_{k}^{t}$-stability of the impulsive systems (7)-(8) by means of the statements given by Corollary 1; and solve the sampled-data control problem based on state estimation for system (1)-(3) in a constructive way.

\section{OBSERVER-BASED CONTROL DESIGN}

In this section a particular choice for $P_{1}$ and $P_{2}$ is proposed. Then, by means of the statements given by Corollary 1 , the control gain matrix $K$ and the observer gain matrix $L$ will be found to provide a stabilization of the state dynamics $x$ as well as an estimation $\hat{x}$, i.e. stabilization of the extended state $\xi$ in (5)-(6). Thus, the following proposition gives a solution to the sampled-data control problem based on state estimation.

Theorem 2. Consider that $P_{1}$ and $P_{2}$ have the following structure for all $\tau_{k}^{t} \in\left[0, T_{i}\right], i=k \in \mathbb{N}$

$$
P_{1}\left(\tau_{k}^{t}\right)=\frac{\tau_{k}^{t} P_{11}+\left(T_{i}-\tau_{k}^{t}\right) P_{12}}{T_{i}}, P_{2}\left(\tau_{k}^{t}\right)=P_{21}+\tau_{k}^{t} P_{22},
$$

where $P_{1 l}=\operatorname{diag}\left(P_{1 l}^{-(1)}, P_{1 l}^{(2)}, P_{1 l}^{-(3)}, P_{1 l}^{-(4)}\right)$, for $l=1,2$, with $P_{1 l}^{(q)}=P_{1 l}^{(q)^{T}}>0$, for $l=1,2, q=\overline{1,4}, P_{1 l}^{-(q)}=$ $\left(P_{1 l}^{(q)}\right)^{-1}$, and $P_{2 l}=P_{2 l}^{T}>0$, for $l=1,2$. Then, the system (5)-(6) is $\mathrm{ED}_{k}^{t}-\mathrm{S}$ if there exist matrices $P_{1 l}^{(q)}$, for $j, l=1,2$, $q=\overline{1,4}$, and $P_{2 l}=P_{2 l}^{T}>0$, for $l=1,2$; such that the LMIs (22)-(23) with

$$
\begin{gathered}
\bar{\phi}_{11}(\Theta)=A P_{11}^{(1)}+P_{11}^{(1)} A^{T}+P_{11}^{(1)} / \Theta-2 P_{11}^{(1)}+\Theta P_{12}^{(1)}, \\
\phi_{12}(\Theta)=P_{11}^{(2)} A+A^{T} P_{11}^{(2)}+\left(P_{11}^{(2)}-P_{12}^{(2)}\right) / \Theta+Q_{12}, \\
\phi_{13}(\Theta)=-2 P_{11}^{(1)}+\Theta P_{12}^{(3)}, \phi_{14}(\Theta)=-2 P_{11}^{(1)}+\Theta P_{12}^{(4)}, \\
\phi_{15}(\Theta)=I_{\xi}^{T} P_{21} I_{\xi}-P_{21}-\Theta P_{22}+Q_{15}, \\
\bar{\phi}_{21}(\Theta)=A P_{12}^{(1)}+P_{12}^{(1)} A^{T}-P_{12}^{(1)} / \Theta, \\
\phi_{22}(\Theta)=P_{12}^{(2)} A+A^{T} P_{12}^{(2)}+\left(P_{11}^{(2)}-P_{12}^{(2)}\right) / \Theta+Q_{22}, \\
\phi_{23}(\Theta)=-2 P_{12}^{(1)}+\Theta P_{12}^{(3)}, \phi_{24}(\Theta)=-2 P_{12}^{(1)}+\Theta P_{12}^{(4)}, \\
\phi_{25}(\Theta)=I_{\xi}^{T} P_{21} I_{\xi}-P_{21}-\Theta P_{22}+Q_{25},
\end{gathered}
$$

hold for the finite set $\Theta \in\left\{T_{\min }, T_{\max }\right\}, Q_{j}=Q_{j}{ }^{T}=$ $\operatorname{diag}\left(Q_{j 1}^{-1}, Q_{j 2}, Q_{j 3}^{-1}, Q_{j 4}^{-1}, Q_{j 5}\right)>0$ for $j=1,2$, fixed $\Lambda_{j}=\Lambda_{j}^{T}>0$ for $j=1,2$, and where

$$
\begin{gathered}
Y_{K_{1}}=K P_{11}^{(1)}, Y_{K_{2}}=K P_{12}^{(1)}, \\
Y_{L_{1}}=P_{11}^{(2)} L, Y_{L_{2}}=P_{12}^{(2)} L ;
\end{gathered}
$$

and constraints (16)-(17) also hold with $c_{1}=\lambda_{\min }\left(P_{11}\right)$, $c_{2}=\lambda_{\max }\left(P_{12}\right), c_{3}=\lambda_{\min }\left(P_{21}\right), c_{4}=\lambda_{\max }\left(P_{21}+\Theta P_{22}\right)$ and $c_{5}=\min \left(\lambda_{\min }\left(Q_{1}\right), \lambda_{\min }\left(Q_{2}\right)\right)$.

${ }^{3}$ The LMI variables are $P_{1 l}^{(q)}$ for $l=1,2, q=\overline{1,4} ; P_{2 l}$ for $l=1,2$; and $Y_{K_{j}}, Y_{L_{j}}$ for $j=1,2$. The matrices $Q_{j l}$ for $j=1,2, l=\overline{1,5}$, can be declared as variables or fixed values; while matrices $\Lambda_{j}$ for $j=1,2$, are fixed. 


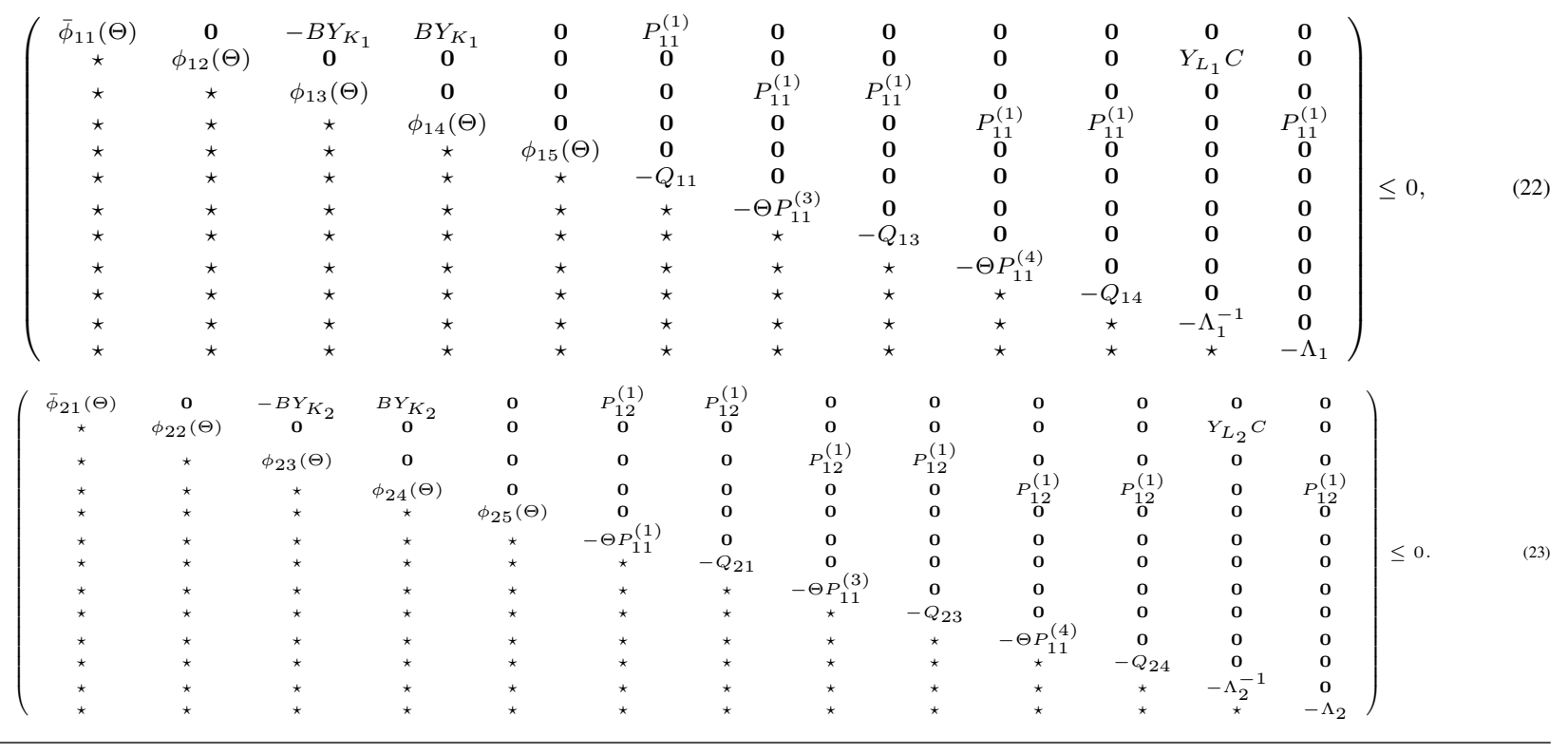
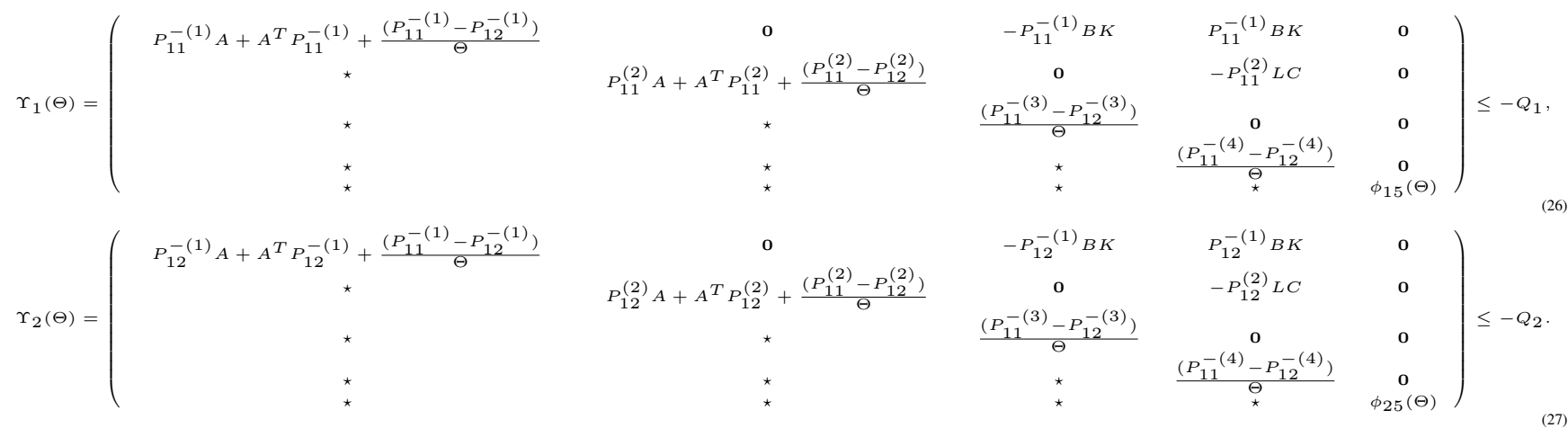

Proof: After some algebraic manipulations on matrix inequality (21) given by Corollary 1, it is possible to obtain inequalities (26) and (27), that should be hold for the finite set $\Theta \in\left\{T_{\min }, T_{\max }\right\}$.

Then, applying some quadratic non-singular transformations, Schur's complement and $\Lambda$-inequality to (26) and (27), respectively; one can obtain the LMIs given by (22) and (23). The complete proof is omitted due to lack of space.

Remark 2. Theorem 2 provides a particular way to solve the proposed problem, i.e. find the control gain matrix $K$ and the observer gain matrix $L$ such that the system (5)-(6) is stable. Then, one can obtain $K$ from (24), and L from (25), using any of the two equalities, respectively.

Note that a different selection for $P_{1}$ and $P_{2}$, even for Lyapunov functions with non-quadratic structure, may decrease the conservatism. More complex tools like sum-of-squares [3], looped-functional approach [5], or convex characterizations [4], may be applied to improve the application of this method.

\section{Simulation Results}

Let us consider system (1)-(2) with

$$
A=\left(\begin{array}{ll}
0 & 1 \\
0 & 0
\end{array}\right), \quad B=\left(\begin{array}{l}
0 \\
1
\end{array}\right) \quad C=\left(\begin{array}{ll}
1 & 0
\end{array}\right) .
$$

This example represents a double-integrator that has a wide range of applications. Theorem 2 is applied together with a bisection-like approach using SeDuMi solver among YALMIP in MATLAB to find a solution for the LMIs (22)(23) and the corresponding control and observer gains.

Based on Theorem 2, it is possible to show that the impulsive system (5)-(6) is EDS for all $2.40>T_{i}>0$ with a set of feasible control and observer gains. The following feasible results are obtained for different fixed values of $T_{i}$ :

$$
\begin{aligned}
L_{\left(T_{i}=0.5\right)} & =\left(\begin{array}{c}
4.0697 \\
1.8351
\end{array}\right), K_{\left(T_{i}=0.5\right)}=\left(\begin{array}{ll}
0.0441 & 0.4030
\end{array}\right), \\
L_{\left(T_{i}=1.0\right)} & =\left(\begin{array}{c}
11.5031 \\
5.4886
\end{array}\right), K_{\left(T_{i}=1.0\right)}=\left(\begin{array}{ll}
0.0522 & 0.4188
\end{array}\right), \\
L_{\left(T_{i}=2.0\right)} & =\left(\begin{array}{c}
9.4047 \\
4.7571
\end{array}\right), K_{\left(T_{i}=2.0\right)}=\left(\begin{array}{ll}
0.0708 & 0.5789
\end{array}\right) .
\end{aligned}
$$

The trajectories of the system, for different values of $T_{i}$, are 

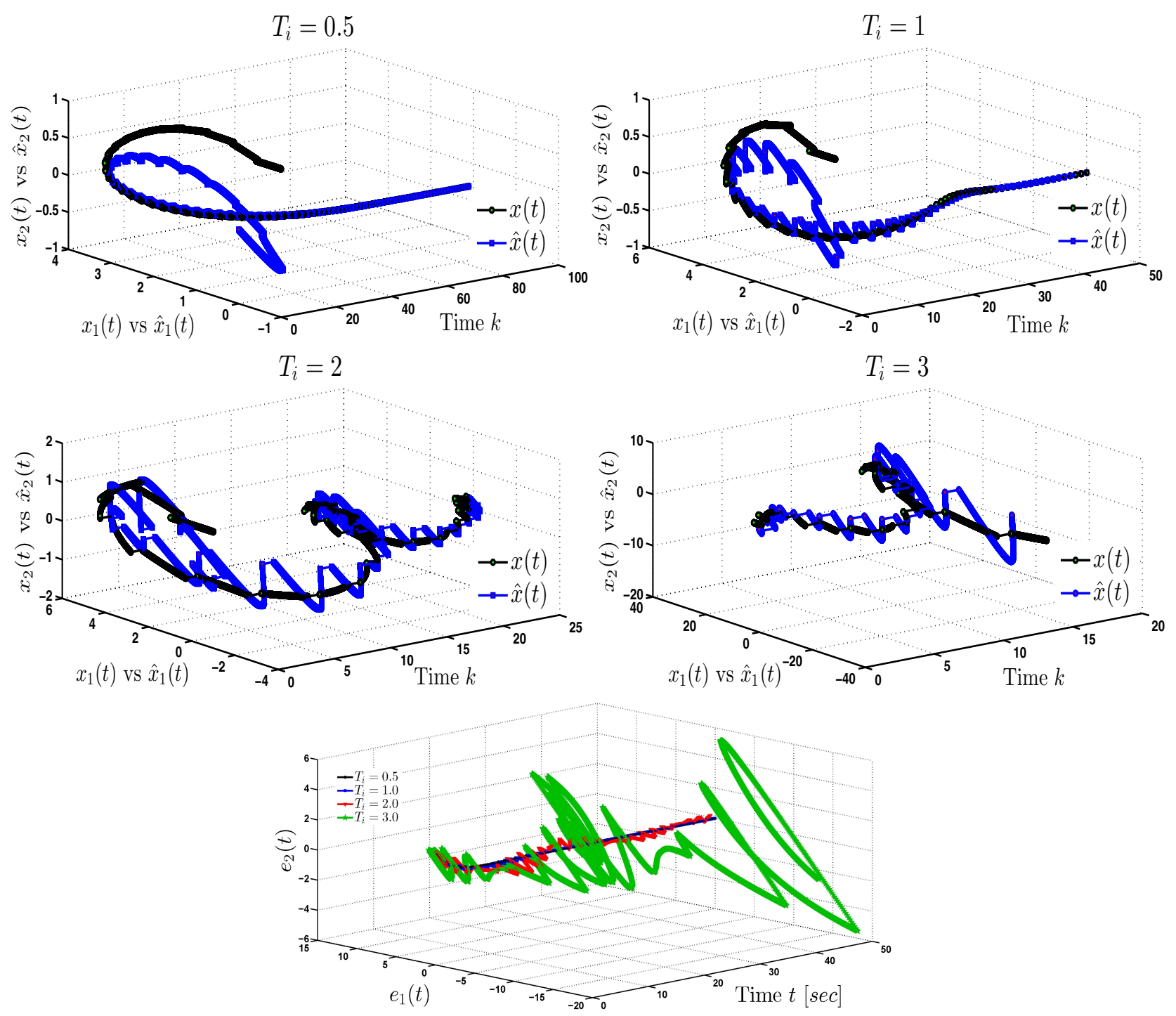

Figure 1. Trajectories of the sampled-data system, their estimations, and the state estimation error for different values of $T_{i}$.

depicted in Fig. 1.

\section{CONCLUSIONS}

In this paper a vector Lyapunov function-based approach for stability of impulsive systems is used to design an observer-based control for linear sampled-data systems. This approach is based on a $2 D$ time domain equivalence and provides a stability analysis based on LMIs. Since the sampled-data control problem based on state estimation may be turned into one of finding conditions for the exponential stability of impulsive systems, the vector Lyapunov function approach is applied to find such conditions expressed in terms of LMIs, and solve the proposed problem for linear sampled-data systems. Some numerical examples illustrate the feasibility of the proposed approach. The analysis of uncertain sampled-data linear/nonlinear systems is in the scope of the future research.

\section{ACKNOWLEDGMENT}

This work was supported in part by Conseil Region Nord-Pas de Calais (ESTIREZ), the Government of Russian Federation (Grant 074-U01), the Ministry of Education and Science of Russian Federation (Project 14.Z50.31.0031), and ANR ROCC-SYS (ANR-14-CE27-0008).

\section{REFERENCES}

[1] T. Ahmed-Ali, I. Karafyllis, and F. Lamnabhi-Lagarrigue. Global exponential sampled-data observers for nonlinear systems with delayed measurements. Systems \& Control Letters, 62:539-549, 2013.

[2] N.W. Bauer, M.C.F. Donkers, N. van de Wouw, and W.P.M.H. Heemels. Decentralized observer-based control via networked communication. Automatica, 49:2074-2086, 2013.

[3] C. Briat. Convex conditions for robust stability analysis and stabilization of linear aperiodic impulsive and sampled-data systems under dwell-time constraints. Automatica, 49:3449-3457, 2013.

[4] C. Briat and A. Seuret. Convex dwell-time characterizations for uncertain linear impulsive systems. IEEE Transactions on Automatic Control, 57(12):3241-3246, 2012. 
[5] C. Briat and A. Seuret. A looped-functional approach for robust stability of linear impulsive systems. Systems \& Control Letters, 61(10):980-988, 2012.

[6] D. Dačić and D. Nešić. Observer design for wired linear networked control systems using matrix inequalities. Automatica, 44(11):2840 2848, 2008

[7] F. Deza, E. Busvelle, J. Gauthier, and D. Rakotopora. High gain estimation for nonlinear systems. Systems \& Control Letters, 18(4):295299, 1992.

[8] E. Fridman. A refined input delay approach to sampled-data control. Automatica, 46(2):421-427, 2010.

[9] E. Fridman, A. Seuret, and J.-P Richard. Robust sampled-data stabilization of linear systems: An input delay approach. Automatica, 40(8):1441-1446, 2004.

[10] E. Fridman, U. Shaked, and V. Suplin. Input/output delay approach to robust sampled-data $h_{\infty}$ control. Systems \& Control Letters, 54:271$282,2005$.

[11] H. Fujioka. A discrete-time approach to stability analysis of systems with aperiodic sample-and-hold devices. IEEE Transactions on Automatic Control, 54(10):2440-2445, 2009.

[12] H. Fujioka. Stability analysis of systems with aperiodic sample-andhold devices. Automatica, 45(3):771-775, 2009.

[13] J.P. Hespanha, P. Naghshtabrizi, and Y. Xu. A survey of recent results in networked control systems. In Proceedings of the IEEE, volume 95, pages 138-162, 2007.

[14] L.-S. Hu, J. Lam, Y.-Y. Cao, and H.-H.Shao. A LMI approach to robust $\mathrm{H}_{2}$ sampled-data control for linear uncertain systems. IEEE Transactions on Systems, Man and Cybernetics, Part B: Cybernetics, 33(1):149-155, February 2003.

[15] V. Lakshmikantham, V. M. Matrosov, and S. Sivasundaram. Vector Lyapunov Functions and Stability Analysis of Nonlinear Systems. Mathematics and its Applications. Kluwer Academic Publishers Group, Dordrecht, 1991.

[16] P. Naghshtabrizi, J.P. Hespanha, and A.R. Teel. Exponential stability of impulsive systems with application to uncertain sampled-data systems. Systems and Control Letters, 57(5):378-385, 2008.

[17] H. Ríos, L. Hetel, and D. Efimov. Stability analysis for impulsive systems: 2d vector lyapunov function approach. 2015. Submitted to IEEE Transactions on Automatic Control. Research Report at https://hal.inria.fr/hal-01280321.

[18] H. Ríos, L. Hetel, and D. Efimov. Vector Lyapunov function based stability for a class of impulsive systems. In Proceedings of the 54th IEEE Conference on Decision and Control, Osaka, Japan, 2015. Accepted.

[19] E. Rogers, K. Galkowski, and D. Owens. Control Systems Theory and Applications for Linear Repetitive Processes, volume 349 of Lecture Notes in Control and Information Sciences. Springer-Verlag, Berlin, 2007.

[20] N. Sivashankar and P.P. Khargonekar. Characterization of the $\mathcal{L}_{2}$ induced norm for linear systems with jumps with applications to sampled-data systems. SIAM Journal on Control and Optimization, 32(4):1128-1150, 1994

[21] N. Yeganefar, N. Yeganefar, M. Ghamgui, and E. Moulay. Lyapunov theory for 2-d nonlinear roesser models: Application to asymptotic and exponential stability. IEEE Transactions on Automatic Control, 58(5):1299-1304, 2013. 